\title{
Review of Tyler Cowen's Stubborn Attachments. San Francisco: Stripe Press, 2018, 158 pp.
}

JOSEPH HEATH

University of Toronto

The past decade has been exceptionally kind to libertarians. Once confined to an isolated and oppressed intellectual minority, thumbing through dog-eared copies of Anarchy, State, and Utopia, while muttering darkly about 'forced labor' and 'self-ownership', the view has since undergone something of a renaissance. Apart from having developed both 'left' and 'right' variants, the theory has largely escaped from the shadow cast by Robert Nozick, so that theorists are now arguing for libertarian conclusions from a wide range of different premises. ${ }^{1}$ The internet has played a crucial role in reinvigorating the movement. Libertarians have formed a number of thriving online subcultures, even attracting many readers and commentators with little sympathy for the view, but intrigued by the vibrancy and intellectual challenge of the positions being discussed. Central to the latter phenomenon has been the economics blog Marginal Revolution, which has served as an extraordinary resource for this community. And central to the blog has been George Mason University professor Tyler Cowen who, as a selfdescribed "infovore" (2010), not only generates a phenomenal volume of provocative posts, but also sifts through other writing at an almost superhuman rate, linking, quoting, and recommending literature on a surprisingly broad range of topics.

But above all, Marginal Revolution has become an invaluable resource for a diffuse group of like-minded individuals, who subscribe to a political position that I like to think of as 'internet libertarianism'not because it has anything to do with the internet, but just because, if you come across someone on the internet claiming to be a libertarian, they will almost always hold something like this position. It is less of a worked-out theory than it is a collection of beliefs. Central to it is the view that government is, in general, bad, while markets are, almost

\footnotetext{
${ }^{1}$ On left libertarianism, see Vallentyne and Steiner (2000), also Otsuka (2003). For doctrinal diversity, see Tomasi (2012), or Levy (2015).
} 
always, good. This normative judgment is taken to follow from two claims, which are seldom clearly distinguished from one another. First, there is the view that markets are good because they promote welfare, while the state is bad because it is inefficient. The second is the view that markets are good because they promote liberty, while the state is bad because it is coercive.

It is this second claim, of course, that confers the title 'libertarian' upon the position, and that distinguishes it from mere liberalism. After all, 'liberals' (in the political-philosophy sense) have for a long time touted the welfare-enhancing qualities of markets. But they have also, for a long time, made the case for the growth of the state-whether it be through regulation, the development of the social safety net, or the provision of public and club goods-in terms of the welfare-enhancing consequences of these interventions. This makes it very difficult to motivate much anti-government rhetoric just by insisting on the importance of efficiency. As a result, those who want to set themselves apart as offering a libertarian defence of the market must say something that goes beyond the standard 'invisible hand' argument.

One way of toughening up the stance in favor of liberty is to jettison the commitment to welfarism. This is the old-school strategy, which one can find in writers like Ayn Rand and Nozick (both of whom regarded the fact that markets make people happy as somewhat incidental to their concerns, and irrelevant from the moral point of view). ${ }^{2}$ But this is too harsh for the modern 'bleeding heart' libertarian, who cares about liberty, but also wants people to be happy. These two positions are, unfortunately, extremely difficult to reconcile. Particularly if the commitment to happiness is interpreted in consequentialist (e.g. utilitarian or quasi-utilitarian) terms, it tends to instrumentalize the commitment to liberty, so that liberty winds up being good if it promotes good consequences, such as general happiness, but dispensable in cases where it does not. This basically rules out extremism in defence of liberty, which, in turn, takes all the fun out of being a libertarian.

Because of this, much of contemporary libertarianism winds up being a paper tiger. It typically starts out with a lot of big talk about contract, freedom, and the blood of patriots, but when push comes to

² See “Man’s Rights” in Rand (1964), also Nozick (1974). 
shove, social welfare winds up doing all the normative work. ${ }^{3}$ The commitment to liberty often shows up as a downstream consequence of some empirically dubious claims about the ineptitude of public servants, and the hidden virtues of private ownership. Central to this reconciliation is the tacit denial that individuals can get locked into states of 'dysphoric freedom', on the model of the prisoner's dilemma, where free choice generates outcomes that are, by common admission, making everyone unhappy.

Cowen's recent book, Stubborn Attachments, is not immune to this difficulty. This short treatise represents Cowen's attempt to take a step back from the barrage of information that he processes every day, in order to provide a more general statement of the philosophical commitments that inform his thinking. For our purposes, it can be thought of as a type of internet-libertarian manifesto. The central question is, what does it bring to the table? The answer is that, while it contains a (perhaps surprisingly large) number of conventional ideas, there is one unconventional one, which Cowen uses in an attempt to resolve the fundamental internet-libertarian dilemma. To preview: Cowen is opposed to temporal discounting. As a result, he wants to 'expand the circle' of moral concern to include all future people. Doing so offers a rather unexpected strategy for resolving the tension between his twin commitments to both consequentialism and a deontological conception of individual rights.

Before getting into the details, a warning: professional philosophers will no doubt find Cowen's book exasperating. Two major problems stand out. First, he is not worried at all about the foundations of his normative commitments, he simply posits them. Thus he posits a commitment to maximizing welfare, along with a host of other goods, and he posits a commitment to "human rights" (2018, 22), but does not really say where they come from. From a philosophical perspective, he might as well be pulling these things out of a hat. Second, many of the commitments that he posits seem incompatible, but instead of worrying about this, he tends to engage in hand-waving of one sort or another. Most obviously, he posits a set of "absolute" (2019) rights (or "(nearly) absolute" (p. 22) in some versions), but then declares himself to be a pluralist about value. Pluralism, however, implies a willingness to make tradeoffs, which in turn makes it difficult to see how the commitment to

\footnotetext{
${ }^{3}$ A good example of this is Easterbrook and Fischel (1991).
} 
rights could be absolute. Furthermore, he does not enumerate the rights that he is committed to-the only specific one he mentions is the right of innocent babies not to be murdered. Without knowing how he feels about more controversial rights, such as the right to property-which he says nothing about-it is impossible to know how much conflict there is likely to be between these rights and the other political values he espouses.

But of course, the book is not intended to be an academic treatise. It is an attempt to organize and provide some structure to a set of widely held ideas, and to provide for his many readers a better sense of 'where he's coming from'. It is therefore unfair to evaluate it by the persnickety standards of academic philosophy. One might treat it then as a profession de foi, and not worry too much about how it hangs together. This is what many commentators have done, and I have little to add to this discussion. What I propose to do, instead, is to offer something of a 'rational reconstruction' of the central argument, presenting it in a more systematic (and defensible) form than Cowen does. I do so because there is an interesting philosophical idea to be found there, which merits serious consideration.

The first thing to note is that, despite going to some lengths to distance himself from both utilitarianism and preference-based welfare consequentialism, Cowen's fundamental moral commitments are consequentialist. One can see this in his discussion of economic growth, which occupies the first two chapters of the book. He adopts from Frank Knight the image of a Crusonia plant, "a mythical, automatically growing crop, which generates more output each period" (p. 28). ${ }^{4}$ Other plants may produce greater yields in the short term, but eventually they wither and die. The Crusonia plant just keeps producing, increasing its yield at a steady rate of (say) 5\%. Given a choice, Cowen observes, between tending one or another crop, one should focus on the Crusonia plant, because in the fullness of time it is guaranteed to outperform any other. More generally, it offers us the opportunity to resolve what he refers to as "aggregation problems" (p. 29). What he has in mind are the distributive conflicts that can be generated through straightforward application of the utilitarian calculus, where the interests of some are

\footnotetext{
${ }^{4}$ The Crusonia plant bears a striking resemblance to the shmoo, which has figured in certain philosophical discussions.
} 
sacrificed in order to produce benefits for others. ${ }^{5}$ Cowen does not propose any formula for resolving these conflicts, instead he urges us to focus on avoiding them, by putting as much of our energy as we can into the cultivation of Crusonia plants. While this may generate conflict and resistance in the short term, if we are sufficiently stubborn in our attachment to them, we can rest assured that, in the long run, they will generate Pareto improvements.

The Crusonia plant is, of course, not entirely fictitious, it is a thinly veiled metaphor for economic growth (p. 29). As a result, Cowen's 'theory of justice', stated as simply as possible, is that we should stop fighting over who gets what, and focus on arranging things so that everyone can get more. This is, of course, a view quite widely held by economists-indeed, it is so conventional that I was somewhat surprised to hear it coming from Cowen. Whatever its merits, however, it is important to note that it is very far from being libertarian. Indeed, from a strictly normative point of view, it more closely resembles Marxism. Marx, it may be recalled, was also quite pessimistic about the possibility of any moral resolution to the distributive conflicts that arise from the joint character of economic activity. He thought that these conflicts were settled in the streets, not at the level of philosophical theory. This is why the history of all hitherto existing society is the history of class conflict (and why morality is nothing but ideology). Capitalism, however, promises to put an end to all this, by producing goods in such abundance that it renders distributive conflict otiose, and therefore permits the formation of a classless society. Marx, of course, believed that this abundance would allow society to abolish the market, whereas Cowen sees quite rightly that it will not. But apart from these institutional details their views have essentially the same normative structure.

The discussion of Crusonia plants also brings to the fore the consequentialism at the heart of Cowen's view. One does not need a growing economy to satisfy the basic deontological constraints that a libertarian like Nozick valued the market for. The central attraction of growth is that it produces increased preference-satisfaction. Cowen is careful to point out that increased consumer satisfaction is not the only value. Non-market values that are worth pursuing include increased

\footnotetext{
${ }^{5}$ He defines 'aggregation', tendentiously, as "how we resolve disagreements and how we decide that the wishes of one individual should take precedence over the wishes of another" (p. 19).
} 
leisure, health, life expectancy, political freedom, and environmental quality. But as he points out, all of these are positively correlated with economic growth, and so expanding the list of goods beyond the merely economic (to what he calls "wealth plus" [p. 30]), does not require any important adjustment of strategy. By maximizing growth, we maximize the sum of good things:

The bottom line is this: the more rapidly growing economy will, at some point, bring about much higher levels of human well-beingand other plural values - on a consistent basis. If some set of choices or policies gives us a higher rate of economic growth, those same choices or policies are akin to a Crusonia plant (p. 41).

Again, this is all fine, but it is also a fairly common liberal sentiment. None of it leads to a particularly libertarian view. Indeed, this framework is one that permits, and perhaps even recommends, any cost-benefit justified state intervention in the economy. This puts us in Cass Sunstein territory. So how do we get from this to the distinctive concern over liberty? One approach would be to build freedom into the consequences, in the way that Amartya Sen does ("it's not the functionings that matter, dummy, it's the space of possible functionings"). Cowen rejects this, on the grounds that it loses the deontological flavour of our commitments to liberty and other individual rights. But what resources does Cowen have, other than standard rule-utilitarianism?

It is at this point that the one genuine peculiarity of Cowen's view surfaces and begins to play an explicit role in the argument. This is his view of temporal discounting. Those who follow Cowen's academic work will know that he published a pair of articles in the early 1990's-one co-authored with Derek Parfit-in which he defended the view that it is morally impermissible to treat the time at which a particular good consequence occurs as a morally salient feature of that event (Cowen and Parfit 1992; Cowen 1992). This commitment to temporal neutrality is a widely held view among philosophers, but rather uncommon among economists. The reason is that economists are accustomed to thinking about investment decisions (as well as economic growth), and worry about the consequences of introducing infinite utility streams into the calculus of costs and benefits. After all, without some sort of discounting, it would be possible to justify arbitrarily large one-time costs, in order to secure a stream of arbitrarily small but recurring 
benefits. Thus economists have habitually bounded the utility functions by introducing a discount factor, which reduces the present value of future payoffs, as a function of how far removed they are in time.

Cowen rejects this (offering instead a commitment to the "overtaking criterion" (128) as a way of comparing utility streams). Following Parfit (1986, 356-357), he draws an analogy between space and time, arguing that where a particular harm occurs is as irrelevant as when it occurs, and so temporal distance is as irrelevant as spatial distance when it comes to the moral assessment of the action that produces it. As Cowen puts it "we can think of the universe as a block of four-dimensional space-time. We would not discount human well-being for temporal distance per se any more than we would discount wellbeing for spatial location per se" (p. 69). One can see the influence of Peter Singer's arguments in the analogy to space. Indeed, one way of thinking about the zero-discounting position is to see it as essentially a Singer-style 'expanding the circle' argument, which claims that the status we assign to our contemporaries is arbitrary, from the moral point of view, and so we must expand our moral horizon to include all future people as well.

While I had previously put it down as something of a curiosity that Cowen held this view, Stubborn Attachments shows that it is in fact quite central to his thinking across a range of different topics. Indeed, it is implicit in his discussion of economic growth, in which the key idea is that favoring the Crusonia plant will eventually pay off. It may not pay off for the current generation, or the next, but eventually people will be better off. This is why, on Cowen's view, we must have stubborn commitments. We must be prepared to ignore the clamouring of people here and now, in order to pursue the policies that will be maximally beneficial in the long term.

The interesting suggestion that Cowen makes-the one that purports to resolve the fundamental tension in internet libertarianism-is that consequentialism, when combined with a commitment to temporal neutrality, allows one to derive a system of rights that function like strict deontic prohibitions in the present. Cowen points out that, given our epistemic limitations, especially given the complexity of causal influences on future events, our commitment to maximizing good consequences in the long term is going to have to translate into the adoption of standing policies. This is the standard rule-utilitarian move. However, as he points out, if one is concerned about all future 
consequences, then the rights that institutionalize the Crusonia plant are going to function as exceptionless constraints in the present, because the sum of good consequences that they generate in the future is so great that they easily outweigh any countervailing considerations in the present. Thus the only grounds one could have for violating rights is the expectation that a failure to do so would somehow threaten human civilization.

In this way, Cowen attempts to pull a deontological rabbit out of a consequentialist hat. The apparent tension between the two forms of moral reasoning arises only because of our tendency to ignore the very distant future-something that, admittedly, most of us do. This is clearly the most interesting idea in Cowen's book, although it is not particularly well-developed, and frankly, I am not sure that it can do the work that he expects it to do. At the same time, the argument is both original and provocative.

I will leave it to others to see if the details can be worked out, because I found myself objecting to features of the argument that arose long before this point. First, the idea that we can 'grow our way out of class conflict', which is central to Cowen's view of the importance of Crusonia plants, is subject to much more serious objections than he acknowledges. One of the big bets made by Marx was that, as industrial production began to lift the curse of Adam, and people became increasingly wealthy, they would also become less concerned about the distribution of wealth. This is what made it possible to imagine a society entering 'post-scarcity' conditions, in which each would happily contribute according to his ability, and so forth. This bet is one that, famously, failed to pay off-average wealth has increased ten-fold, and yet individuals are not even a tiny bit less possessive than they were a century ago. There are various accounts for why this is, but the most important involves the suggestion that, as people become wealthier, an increased fraction of their consumption becomes instrumental to the attainment of status, which is essentially zero-sum.

One of the most surprising features of Cowen's book is that, given his normative framework, he is not more worried about status competition. Thorstein Veblen and Fred Hirsch make no appearance in his discussion. Cowen deals with some concerns about status in a section dedicated to the claim that increased growth, beyond a certain point, fails to promote happiness, but he says nothing at all about the concern that growth does nothing to diminish distributive conflict (and 
thus does nothing to resolve 'aggregation problems'). This is especially peculiar given that, in his contributions as a public intellectual, Cowen often claims that the arguments being traded back and forth by other commentators, as well as the political positions taken, are merely disguised attempts to raise or lower the status of different groups. (Indeed, his well-known heuristic for reading op-ed articles is that most can be reduced to the claim that one group, with whom the author affiliates, should see its status rise, while some other group, with whom the author disassociates, should see its status fall.) Cowen has even argued that the literature on growth and happiness should be interpreted as an attempt by intellectuals to raise their relative status: "When happiness research indicates that money brings more happiness only up to a point, this is a popular result. That perspective lowers the status of this monied class by showing they really aren't that happy" (Cowen, 2008).

And yet, if intellectual life is all just a disguised form of status competition, how hard is it to believe that economic life-once the basic necessities have been met-is also just an indirect or disguised form of status competition? And how hard is it to believe that hundreds of years in the future, consumption will have become entirely instrumental to relative status concerns? But if this is true, then the Crusonia plant of economic growth is not the open-ended source of gain that Cowen imagines it to be, nor can we have any reasonable expectation that it will allow us to avoid dealing with questions of distributive justice. Consider Pierre Bourdieu's claim that aesthetic value is merely a disguised form of status seeking (Bourdieu 1984). I have no doubt that Cowen rejects this claim-he appears to have almost endearingly non-cynical views on aesthetic taste-but he should at least be worried that it is true, since his normative position is one that relies so heavily upon the positivesum character of social life as a way of circumventing difficult philosophical questions.

I was also unpersuaded by Cowen's commitment to temporal neutrality, along with his conviction that we must 'expand the circle' to include all future people. This is a very complex issue, which I cannot get into the details of here. ${ }^{6}$ There is not much of an argument in the book, other than the bald assertion that time is just like space, both irrelevant from the moral point of view. It is worth noting, however, that

\footnotetext{
${ }^{6}$ For discussion, see Heath (2017).
} 
Cowen's formal derivation of temporal neutrality, in his paper "Consequentialism Implies a Zero Intergenerational Rate of Discounting", relies upon the most objectionable feature of consequentialism to produce that result. In this paper, he introduces an axiom of "person neutrality", which states that "a benefit for one person is equally good as the same benefit for another person" (Cowen 1992, 163). He then claims that "neutrality across generations becomes a natural extension of the traditional consequentialist belief in person neutrality within a single generation" (166). This idea-that one can simply take away happiness from one person and give it to someone else, and that these redistributions are all a matter of indifference from the moral point of view-is what critics like Rawls have in mind when they say that consequentialism fails to respect the distinctness of persons.

More generally, the commitment to temporal neutrality helps to explain a noticeable peculiarity in Cowen's public commentary, a trait that some have described as a lack of empathy. As a long-time reader of Cowen's work, I have also found it difficult on occasion to see how a person who is so concerned about promoting welfare could exhibit so little concern for actual human suffering. There is something rather Olympian, for instance, about Cowen's insistence that, as a society, we spend far too many of our health care dollars caring for sick people, and not nearly enough investing in medical research. He often comes across like the proverbial socialist who loves the people, just not any specific person. Reading Stubborn Attachments has helped me to understand the underlying rationale for this stance. His zero-discounting principle is one that allows him to care deeply about humanity, without caring too much about actual people-i.e. the small subset of persons who happen to be alive at the moment. On Cowen's view of things, caring about the suffering of real, live human beings shows up as a prejudice, since we are arbitrarily privileging the interests of those who occupy a block of space-time contiguous to our own.

And here, finally, we come to one of the most important differences between philosophy and economics. In philosophy, what one man considers a conclusion will more often be regarded, by another, as a reductio. 


\section{REFERENCES}

Bourdieu, Pierre. 1984. Distinction, translated by Richard Nice. Cambridge, MA: Harvard University Press.

Cowen, Tyler. 1992. "Consequentialism Implies a Zero Rate of Intergenerational Discount." In Justice Between Age Groups and Generations, edited by Peter Laslett and James S. Fishkin, 162-168. New Haven, CT: Yale University Press.

Cowen, Tyler. 2008. "Move on - This Isn't True Here.” Marginal Revolution, July 26, 2008. Accessed April 2, 2019. <https://marginalrevolution.com/ marginalrevolution/2008/07/xxxxxxx.html>.

Cowen, Tyler. 2010. The Age of the Infovore. London: Plume.

Cowen, Tyler. 2019. "The Case for the Longer Term." Cato Unbound, January 9, 2019. Accessed April 2, 2019. <https://www.cato-unbound.org/2019/01/09/tylercowen/case-longer-term>.

Cowen, Tyler., and Derek Parfit. 1992. “Against the Social Discount Rate.” In Justice Between Age Groups and Generations, edited by Peter Laslett and James S. Fishkin, 144-161. New Haven, CT: Yale University Press.

Easterbrook, Frank H., and Daniel R. Fischel. 1991. The Economic Structure of Corporate Law. Cambridge, MA: Harvard University Press.

Heath, Joseph. 2017. "Climate Ethics: Justifying a Positive Social Time Preference." Journal of Moral Philosophy, 14 (4): 435-462.

Levy, Jacob T. 2015. Rationalism, Pluralism and Freedom. Oxford: Oxford University Press.

Nozick, Robert. 1974. Anarchy, State, and Utopia. New York, NY: Basic Books.

Otsuka, Michael. 2003. Libertarianism without Inequality. Oxford: Clarendon.

Parfit, Derek. 1986. Reasons and Persons. Oxford: Clarendon.

Rand, Ayn. 1964. The Virtue of Selfishness. New York, NY: Signet.

Tomasi, John. 2012. Free Market Fairness. Princeton, NJ: Princeton University Press.

Vallentyne, Peter, and Hillel Steiner, eds. 2000. Left-Libertarianism and Its Critics. London: Palgrave.

Joseph Heath is Professor in the Department of Philosophy and the Munk School of Global Affairs and Public Policy at the University of Toronto. A fellow of the Royal Society of Canada and the Trudeau Foundation, Heath is the author of several books, both popular and academic. His most recent, Morality, Competition and the Firm (Oxford, 2014), is a collection of papers on business ethics and the normative foundations of market economies. He is also the author of Enlightenment 2.0 (HarperCollins, 2014) and, with Andrew Potter, The Rebel Sell (HarperCollins, 2004).

Contact e-mail: <joseph.heath@utoronto.ca>

Website: <chass.utoronto.ca/ jheath> 